\title{
Letter to the Editor-Consensus on Retrograde Extrapolations
}

Peter D Maskell

Michael Scott-Ham

This is the author version of a letter to the editor, which has been published in final form at

https://doi.org/10.1111/1556-4029.13922. This article may be used for non-commercial purposes in accordance with Wiley Terms and Conditions for SelfArchiving. 
Letter to the Editor-Consensus on Retrograde Extrapolations

Sir,

We read with interest the recent article by Lebay \& Logan Calling for a consensus regarding retrograde extrapolation to determine blood alcohol content (BAC) in driving under the influence (DUI) cases (1). We agree that there should be a consensus for retrograde extrapolation and also feel that there should be a consensus for other alcohol calculations such as estimating BAC based on the number of drinks consumed or estimating alcohol consumption based on BAC. These calculations may be required for cases in which the "hip flask" defence (where alcohol was allegedly consumed after an offence and before a breath/blood sample was obtained) or in sexual assault cases.

In the UK and Ireland a freely available set of guidelines (2) have been agreed by the United Kingdom and Ireland Association of Forensic Toxicologists (UKIAFT), the group that represents practicing forensic toxicologist in those jurisdictions. These guidelines have been endorsed by the UK Forensic Science Regulator (3). This document covers alcohol calculations, if and when calculations should be performed, blood to breath ratios, alcohol elimination rates and a standardised approach for performing calculations. Although some parts of the guidelines may not be relevant to all legal jurisdictions they should give a good starting point for further discussions for a consensus.

\section{References}

1. Labay, L. and Logan, B. (2018) Letter to the Editor - Call for a Scientific Consensus Regarding the Application of Retrograde Extrapolation to Determine Blood Alcohol Content in DUI Cases. Journal of Forensic Sciences, 63, 1602-1603. https://doi.org/10.1111/1556-4029.13846.

2. UKIAFT Guidelines for Performing Alcohol Technical Defence Calculations (2014). http://www.ukiaft.co.uk/image/catalog/documents/UKIAFT ATD v2 1.pdf (5 September 2018).

3. Forensic Science Regulator (2015) Alcohol back calculation for road traffic investigations. https://www.gov.uk/government/publications/alcohol-back-calculation-for-road-trafficinvestigations (5 September 2018).

Peter D Maskell $\quad$ Abertay University, Dundee. UK

Michael Scott-Ham Principal Forensic Services, Kent. UK. 